\title{
Tumores pulmonares en pediatría
}

\author{
MARÍA ELENA UCAR G.*, OSVALDO IBÁÑEZ B.*, \\ CELIA FERRARI R.* y DANIEL POLLONO F.**
}

\section{Pulmonary tumors in pediatrics}

In patients under 15 years of age primary lung tumors are infrequent, most thoracic tumors being originated in the mediastinum or the thoracic wall. The great majority of pulmonary masses are nonneoplastic corresponding to inflammatory processes or malformations. Amongst neoplasms metastasis from solid extracraneal tumors are the predominant lesions. Other malignant neoplasms are: bronchial carcinoid, mucoepidermoid carcinoma, pulmonary lymphoma, pleuropulmonary blastoma and metastasis. In the spectrum of benign lesions the following are found: miofibroblastic inflammatory tumor, nodular lymphoid hyperplasia and hamartomas. The diagnosis of primary pulmonary neoplasms is frequently late because of its low incidence, lack of clinical suspicion and the variability of its manifestations. Radiological and tomographical signs are very proteiform and unspecific, representing a great diagnostic challenge.

Key words: Pulmonary neoplasms in children, pulmonary metastasis.

\section{Resumen}

En pacientes menores de 15 años los tumores pulmonares primarios son infrecuentes, generalmente los tumores torácicos son de origen mediastínico o de la pared torácica. La gran mayoría de las masas pulmonares son de origen no neoplásico, correspondiendo a procesos inflamatorios o malformaciones. Dentro de las neoplasias pulmonares, las metástasis de tumores sólidos extracraneanos son las lesiones predominantes. En el espectro de lesiones benignas se encuentran el tumor miofibroblástico inflamatorio, la hiperplasia nodular linfoidea, los sindromes linfoproliferativos y los hamartomas. Entre las neoplasias malignas se incluyen el tumor carcinoide bronquial, carcinoma mucoepidermoide, linfoma pulmonar, blastoma pleuropulmonar y las metástasis. El diagnóstico de las neoplasias primarias pulmonares frecuentemente es tardio, por su baja incidencia y la falta de sospecha clínica o por su presentación atípica. Los hallazgos radiológicos y tomográficos de los tumores pulmonares son muy proteiformes, según su estirpe y lugar de origen, y no son especificos en la mayoría de los casos, constituyendo habitualmente un gran desafio diagnóstico.

Palabras clave: Neoplasias pulmonares en niños, metástasis pulmonares.

\section{Introducción}

En el tórax de los pacientes menores de 15 años, son más frecuentes que los tumores primarios del pulmón, los del mediastino y de la pared torácica, siendo además necesario considerar que la gran mayoría de las masas pulmonares son de origen no neoplásico correspondiendo a procesos inflamatorios o malformaciones.

Las neoplasias de pulmón más frecuentes en niños, son lesiones secundarias y generalmente corresponden a metástasis, de tumores sólidos malignos extracraneanos. La relación aproximada entre los tumores primarios y las metástasis, es 5:95 según estadística del Servicio de Oncología de nuestro hospital entre los años 2000 a 2008. Las neoplasias primarias pulmonares son infrecuentes, generalmente de diagnóstico tardío, inicialmente sus manifestaciones clínicas se confunden con un proceso infeccioso, produciendo

\footnotetext{
* Servicio de Radiología y Diagnóstico por Imágenes, Hospital de Niños Sor María Ludovica. La Plata. Argentina.

** Servicio de Oncología, Hospital de Niños Sor María Ludovica. La Plata. Argentina.
} 
a veces compresión de estructuras adyacentes. $\mathrm{Su}$ persistencia en estudios radiológicos es una forma frecuente de presentación.

Es importante consignar que siempre debemos considerar, dentro de los diagnósticos diferenciales, los pseudotumores usualmente de origen extrapulmonar, tales como trenzas, brotes mamarios o lesiones de la pared.

El primer estudio es generalmente la radiografía $(\mathrm{Rx})$ de tórax, en la cual la presencia de una imagen inusual o que no se correlaciona con su presentación clínica, debe hacer sospechar una masa pulmonar; la proyección lateral puede ser útil para valorar compresión o desplazamiento de tráquea, y definir la topografía predominante de la lesión. Permite este estudio orientar o recomendar métodos adicionales de imágenes para caracterizar mejor la lesión, su extensión y relación con estructuras vitales.

La tomografía computada (TC) con contraste e.v., es el estudio recomendado para evaluar las masas pulmonares y/o mediastinales y permite estudiar el parénquima pulmonar y la vía aérea, caracterizar la lesión y discernir la extensión del tumor, la relación de la masa con la vía aérea, grandes vasos o pared torácica. Debe considerarse, sin embargo, el riesgo asociado a la radiación ionizante al emplearse este método diagnóstico, no aplicando en niños protocolos de adultos: Si se dispone deben utilizarse aquellos determinados automáticamente por el peso del paciente, o bien disminuir manualmente la radiación acorde con el principio ALA$\mathrm{RA}$, de las siglas en inglés del concepto utilizar la radiación tan baja como sea posible para alcanzar una imagen razonablemente aceptable ${ }^{1}$.

En la actualidad, la adquisición de informacion con la TC multidetectores (MDCT), permiten obtener imágenes de altísima calidad y definición, con la posibilidad de realizar una amplia gama de procesamiento, entre las que resulta de gran utilidad las reconstrucciones coronales y sagitales, para valorar la extensión del tumor e invasión de zonas adyacentes.

En la pesquisa de metástasis pulmonares, la adquisición de imágenes continuas sin administración de contraste e.v., es util en pacientes pediátricos. La posibilidad de realizar imágenes con protocolos de máxima intensidad (MIP) mejora la sensibilidad, especialmente en pequeños nódulos pulmonares.

La resonancia magnética ( $\mathrm{RM})$ es el método de elección para evaluar lesiones de partes blandas, pared torácica, mediastino, lesiones que contienen fluido y las que invaden el canal medular. No utiliza radiación ionizante, pero en niños pequeños generalmente requiere anestesia.

\section{Tumores benignos}

\section{a. Tumor miofibroblástico inflamatorio}

También conocido como pseudotumor inflamatorio o granuloma de células plasmáticas; es el más frecuente de los tumores benignos en niños y representa aproximadamente el 50\% de éstos. Generalmente se presenta en mayores de 5 años $(75 \%)$. Está considerada dentro del espectro de lesiones linfoproliferativas reactivas benignas, junto a linfoproliferaciones asociado a bronquios y mucosas, y desórdenes linfoproliferativos postrasplante ${ }^{2}$.

Se caracteriza por una proliferación localizada de células inflamatorias monoclonales generalmente células plasmáticas, linfocitos, eosinófilos y células mesenquimales en forma de huso y miofibroblastos. Hay dos tipos histológicos: tipo celular, rico en células plasmáticas o granulomas de células plasmáticas y tipo fibrohistiocítico ${ }^{3}$. El subtipo rico en células plasmáticas se ha relacionado a enfermedades pulmonares asociadas con aumento de inmunoglobulina G4, por inflamación esclerosante del tejido conectivo intrapulmonar ${ }^{4}$.

La etiología es multifactorial, existiendo dos hipótesis acerca de su origen. Algunos autores sugieren una respuesta reparadora no regulada ante un daño pulmonar, por trauma, infección por virus de Epstein-Barr, Herpes 8 o gérmenes inusuales como Nocardia, Actinomices y Klebsiella ${ }^{5}$. La otra vertiente sugiere que el tumor miofibroblástico inflamatorio es una formación neoplásica, ya que se ha aislado una anomalía citogenética clonal que codifica el gen ALK en el cromosoma 2 p 23, también asociado a algunos tumores de partes blandas 6 .

Generalmente los pacientes presentan fiebre, disminución de peso y malestar, pero hasta el $30 \%$ de los niños están asintomáticos al momento del diagnóstico 7 .

Se han reportado tres aspectos tomográficos.

1. El más frecuente corresponde a una masa única periférica, redondeada, bien circunscrita en los lóbulos inferiores, de 3 a $4 \mathrm{~cm}$ de diámetro, sin invasión de estructuras adyacentes, puede tener calcificaciones (Figura 1).

2. En hasta un $20 \%$ de los pacientes se puede presentar como una masa endobronquial, generalmente pequeña, sin calcificaciones que simula un adenoma ${ }^{8}$.

3. La tercera forma de presentación es una gran masa espiculada, con áreas de necrosis o excavación. Si bien puede presentar realce variable luego de la administración de contraste e.v. en $\mathrm{TC}$, no presenta un aspecto característico (Figura 2). 

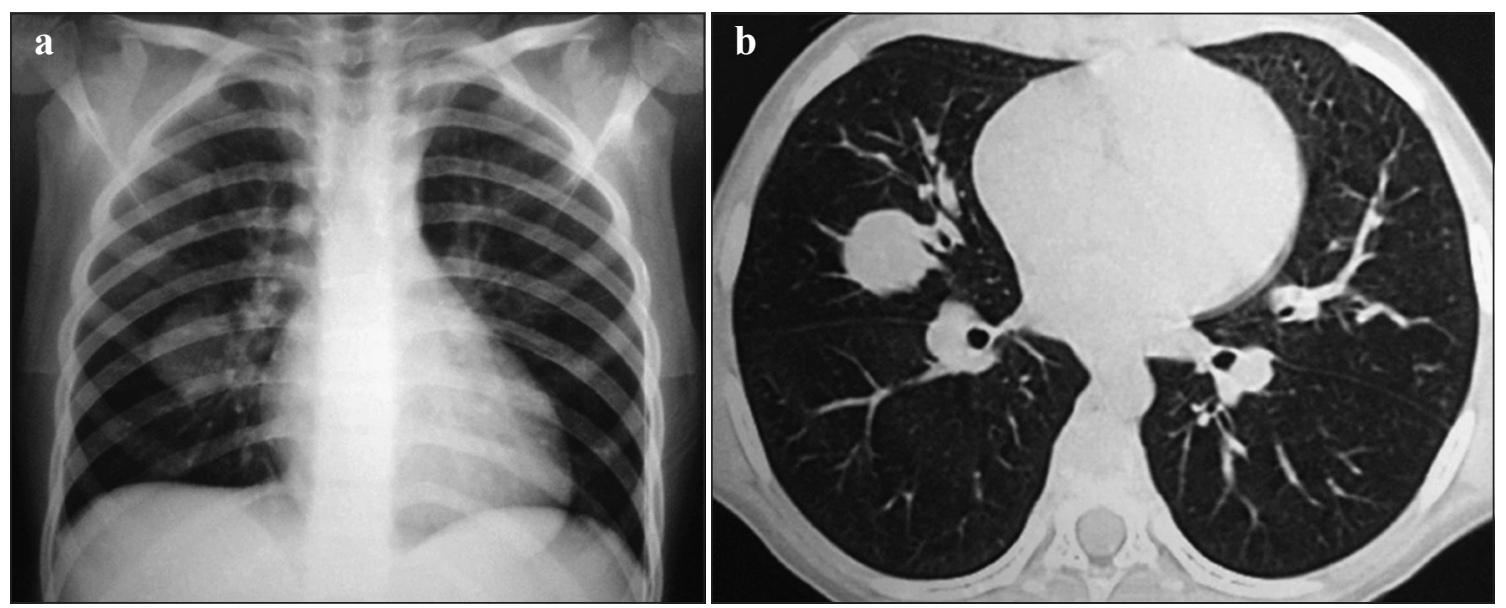

Figura 1 a, b. Tumor miofibroblástico inflamatorio: Control periódico de paciente con TMO para tratamiento de leucemia, con cinco años de evolución; a) Rx de tórax: Imagen redondeada, radiopaca, en hemitórax derecho; b) TC: Imagen nodular en lóbulo medio.
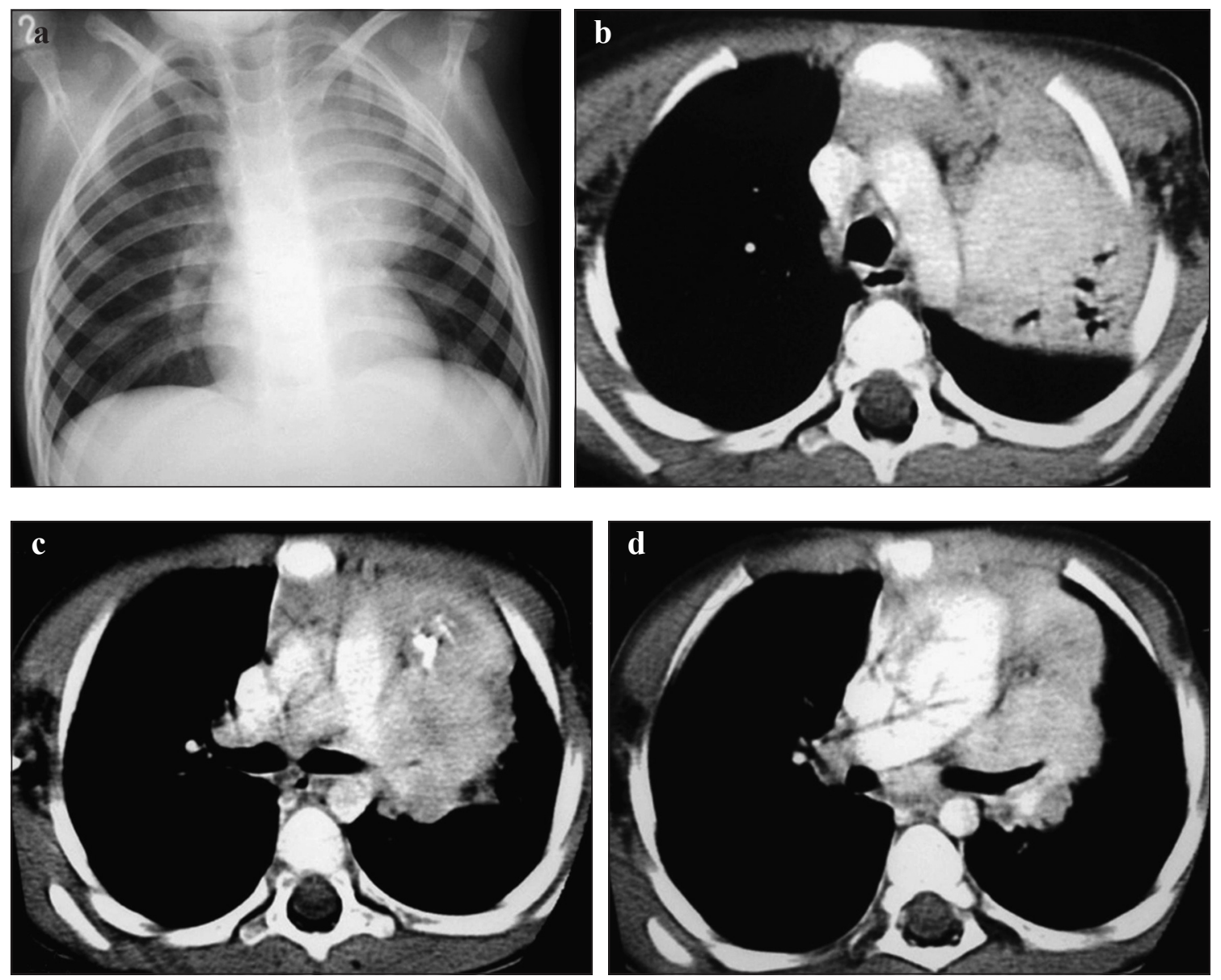

Figura 2 a-d. Tumor miofibroblástico inflamatorio. Paciente de 5 años que consulta por tos; a) Rx de tórax: Imagen redondeada en hemitórax izquierdo que presenta signo de la silueta con margen mediastinal superior; b-d) TC de tórax con contraste e.v: Masa yuxtamediastinal con calcificaciones, realce heterogéneo y bordes lobulados. 
La forma invasiva de esta entidad es más frecuente en pediatría que en adultos, condicionando afectación tanto del mediastino, como grandes vasos, vía aérea y pared torácica: Si al momento del diagnóstico el tumor excede el parénquima pulmonar, la posibilidad de recurrencia local es hasta de 35 a $46 \%{ }^{9}$.

\section{b. Hiperplasia nodular linfoidea}

La hiperplasia nodular linfoidea (HNL) es un raro desorden benigno, denominado inicialmente en 1963 como "pseudolinfoma"; en 1983 Kradin y Mark realizaron su descripción histológica característica ${ }^{10}$ y en 1999 la OMS confirmó su existencia como entidad específica y es considerada en la actualidad una proliferación linfoidea reactiva localizada ${ }^{2}$. Su causa es desconocida y algunos autores la consideran dentro del grupo de lesiones pulmonares asociadas a enfermedades por Ig G4, también han reportado asociación con enfermedades autoinmunes, especialmente con el Síndrome de Sjögren ${ }^{11}$.

Dentro del término "pseudolinfoma" se incluye al linfoma de tejido linfoideo asociado a mucosa (MALT), la hiperplasia nodular linfoidea y otras enfermedades linfoproliferativas de bajo grado ${ }^{12}$.

La hiperplasia nodular linfoidea se presenta como una masa bien delimitada, de tejido linfoideo abundante con centros germinales reactivos, células plasmáticas maduras interfoliculares y linfocitos pequeños reactivos. Por inmunohistoquímica se trata de una población policlonal de linfocitos y células plasmáticas. La gran diferencia con linfoma asociado a MALT es que este último es una lesión infiltrativa difusa, con linfocitos polimórficos, y en la mayoría de los casos, población monoclonal. Aunque algunos autores sostienen que la relación entre HNL y linfoma asociado a MALT es dudosa, ya que la HNL puede ocultar focos de linfoma y el linfoma asociado a MALT tiene centros germinales reactivos ${ }^{13}$.

La HNL se halla dentro del mismo espectro de la neumonía intersticial linfocítica, por infiltración de tejido linfoideo asociado a bronquios (BALT), junto con la hiperplasia folicular o bronquiolitis folicular. Otro de los diagnósticos diferenciales es el linfoma de células B de bajo grado ${ }^{14}$.

La mayoría de los pacientes con HNL son asintomáticos y su diagnóstico se realiza en la madurez.

En la TC se observa generalmente una imagen nodular, única, de aspecto sólido, de aproximadamente 2 a $4 \mathrm{~cm}$ de diámetro, ocasionalmente múltiples; y en el 90\% de los casos de localización subpleural ${ }^{13}$. La imagen nodular puede presentar área de vidrio esmerilado en su periferia, conformando el signo del halo. En el 30\% de los casos puede identificarse adenopatías hiliares o mediasti- nales. En nuestra experiencia, la única paciente con diagnóstico de HNL, se presentó con una imagen radiopaca en el tercio medio del hemitórax derecho en la radiografia de tórax. En la TC se observó una zona de condensación parenquimatosa, sin broncograma aéreo, localizado en segmento lateral de lóbulo medio derecho y una masa parahiliar derecha, con bordes espiculados y líneas irregulares o bandas parenquimatosas. Adicionalmente existía una imagen nodular subpleural en el ápice pulmonar izquierdo (Figura 3).
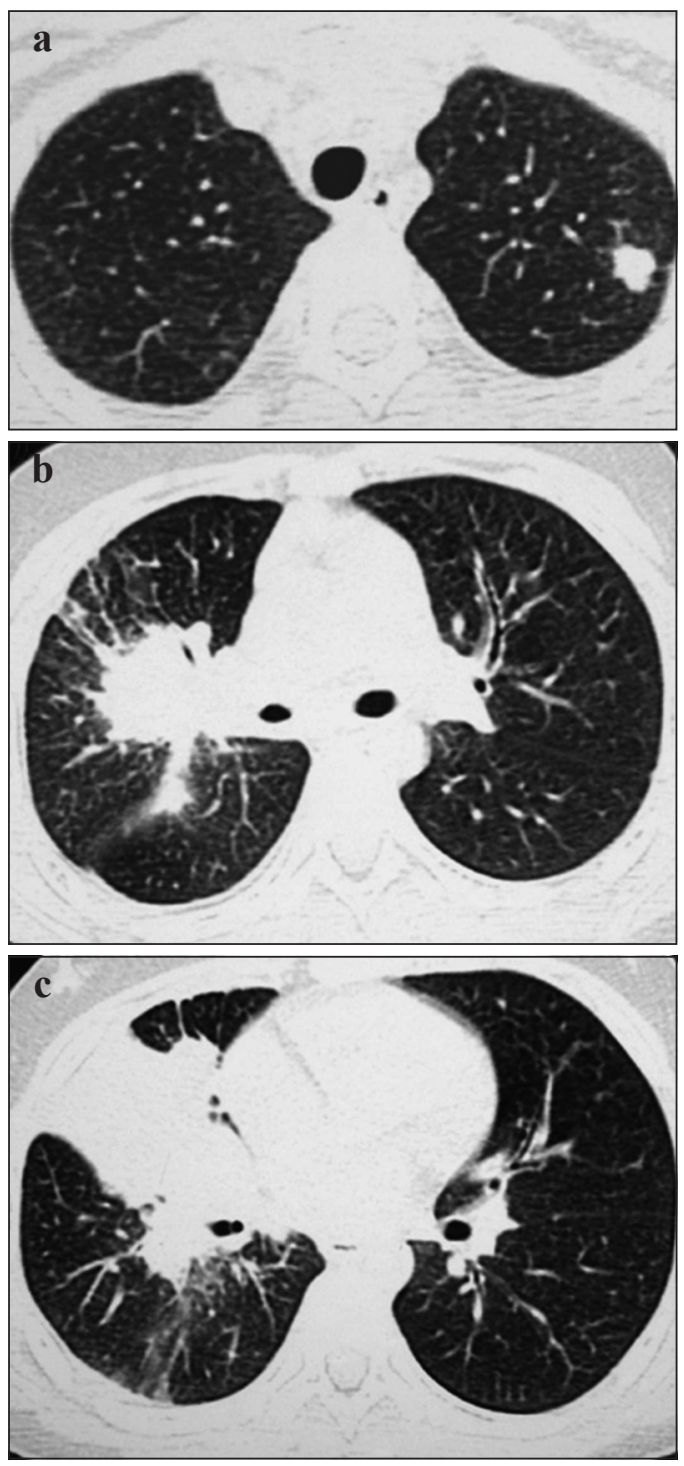

Figura 3 a-c. Hiperplasia nodular linfoidea; a) Imagen nodular subpleural en ápice pulmonar izquierdo; b) Masa parahiliar derecha con bordes espiculados y líneas irregulares o bandas parenquimatosas; c) Condensación parenquimatosa, sin broncograma aéreo en su interior, localizado en segmento lateral de lóbulo medio derecho. 


\section{c. Síndrome linfoproliferativo post-trasplante}

El síndrome linfoproliferativo post-trasplante se origina más frecuentemente en niños que en adultos, generalmente luego de trasplante pulmonar o cardiopulmonar ${ }^{15}$, aunque también se puede desarrollar luego de trasplante de órganos sólidos o de médula ósea. También se puede desarrollar en pacientes con inmunosupresión severa por infección HIV.

Se considera una proliferación linfoidea reactiva benigna ${ }^{2}$, con un espectro histológico que abarca desde la hiperplasia linfoidea policlonal hasta el linfoma monoclonal de células B, cuando la enfermedad está avanzada, por retraso diagnóstico. En la mayoría de los casos está asociado a infección por virus de Epstein-Barr, en pacientes seronegativos que desarrollan la enfermedad primaria por el virus luego del trasplante; y con mayor incidencia en pacientes que han recibido corticoterapia en altas dosis y ciclosporina. Generalmente las imágenes pulmonares no son específicas, con un gran abanico de presentación, desde nódulos únicos o múltiples, masas de aspectos sólidos o excavados, consolidación, adenopatías; y el diagnóstico debe realizarse por biopsia (Figura 4).

\section{d. Hamartoma}

Los hamartomas pulmonares representan aproximadamente el $20 \%$ de los tumores benignos, son generalmente considerados anomalías del desarrollo pulmonar, ya que están compuestos por tejido pulmonar con configuración anómala. Pueden localizarse en parénquima pulmonar o raramente en lumen bronquial $^{8}$. Frecuentemente son diagnosticados de modo incidental en mayores de 40 años, ya que generalmente son asintomáticos.

El aspecto radiológico característico es una opacidad redondeada en la periferia del parénquima, en el $10 \%$ de los casos presentan calcificaciones que son curvilíneas, especuladas, o el clásico aspecto de "palomitas de maíz", cuanto mayor su tamaño, más calcificaciones hay en su interior (Figura 5). En el 30\% de los casos se
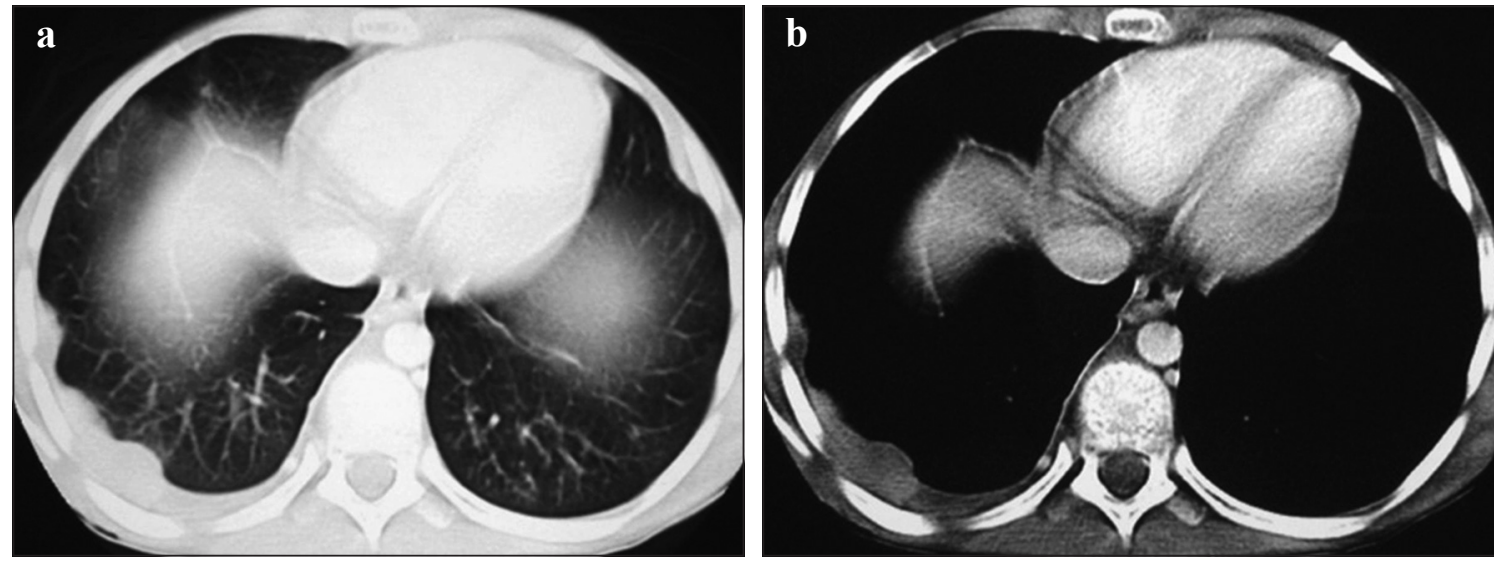

Figura 4. a, b. Síndrome linfoproliferativo post-trasplante; a) TC en ventana pulmonar; b) TC en ventana mediastínica: Engrosamiento nodular de la pleura con escaso líquido asociado.
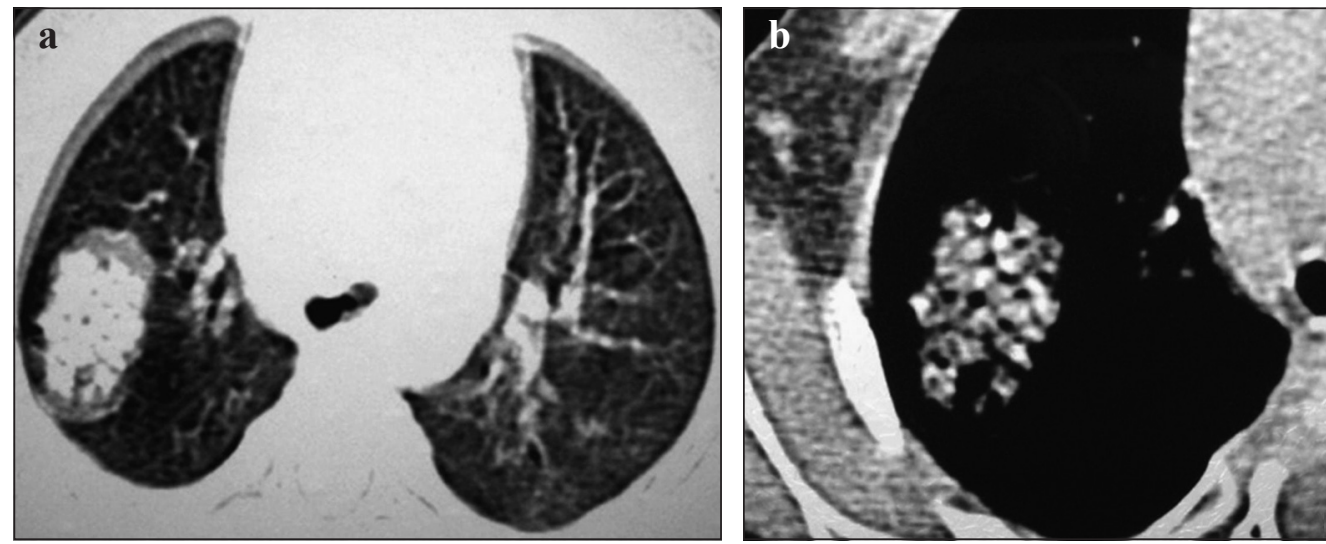

Figura 5 a, b. Hamartoma: Hallazgo radiológico; a) TC en ventana pulmonar; b) TC en ventana mediastinal: Imagen nodular con calcificaciones en "palomita de maíz" y algunas áreas con densidad grasa. 
asocia a contenido graso, indicativo de benigni$\mathrm{dad}^{8}$. El condroma pulmonar es infrecuente, tiene calcificaciones y resulta dificultoso diferenciarlo del hamartoma en las imágenes.

\section{Tumores malignos}

\section{a. Tumor carcinoide bronquial}

Tradicional y erróneamente considerado como un adenoma bronquial. Esta denominación ampliamente usada para todos los tumores de las glándulas traqueobronquiales, agrupa lesiones de bajo grado de malignidad con capacidad de diseminarse, con excepción del verdadero adenoma mucinoso, extremadamente raro $^{8}$. Los tumores englobados en este grupo son el carcinoma mucoepidermoide, tumor carcinoide bronquial y carcinoma quístico adenoide o cilíndrico.

La denominación "adenoma" debe evitarse porque es inadecuada. El tumor carcinoide no es uniformemente glandular ni absolutamente benigno; es un tumor neuroendocrino del sistema APUD, que se origina de las células de Kulchitsky del epitelio respiratorio. En pediatría raramente se presenta con síndrome carcinoide dado por las sustancias aminoprecursoras y descaboxilasas que secretan las células tumorales, excepto que tenga metástasis hepáticas ${ }^{16}$.

Es el tumor más frecuente del árbol bronquial representa el $67 \%$ de los tumores traqueobronquiales malignos ${ }^{7}$. Generalmente se localizan en un bronquio lobar $(75 \%)$, menos frecuentemente en bronquio fuente $(10 \%)$ y parénquima pulmonar, $(15 \%)^{17}$. Tienen un componente luminal, mural y extrabronquial. La mayoría de los pacientes se presentan con atelectasia persistente en Rx de tórax; y el diagnóstico se realiza por broncoscopia cuando se pesquisa cuerpo extraño.

En la TC se puede observar una masa ovoidea, discretamente lobulada, de localización endobronquial, que puede obliterar la luz bronquial de modo parcial o total (Figura 6), y por su vascularización presenta gran avidez por el contraste endovenoso. A veces se puede detectar una lesión "iceberg", cuando el componente endobronquial es relativamente pequeño con respecto al volumen tumoral total ${ }^{18}$. Muchas veces resulta dificultoso determinar la real extensión del tumor dado el gran componente extrabronquial, y se puede asociar una masa hiliar. La presentación como nódulo pulmonar solitario en topografía periférica es poco frecuente. Otros hallazgos tomográficos son condensación, atelectasia, atrapamiento aéreo, y mucocele. Raramente se advierten calcificaciones, a diferencia de los adultos. La incidencia de metástasis puede ser del 5 a $20 \%$ de los casos por diseminación linfática ${ }^{19}$. Según los reportes en pediatría la resección quirúrgica es el mejor tratamiento y la sobrevida es del $90 \%{ }^{17,20}$.
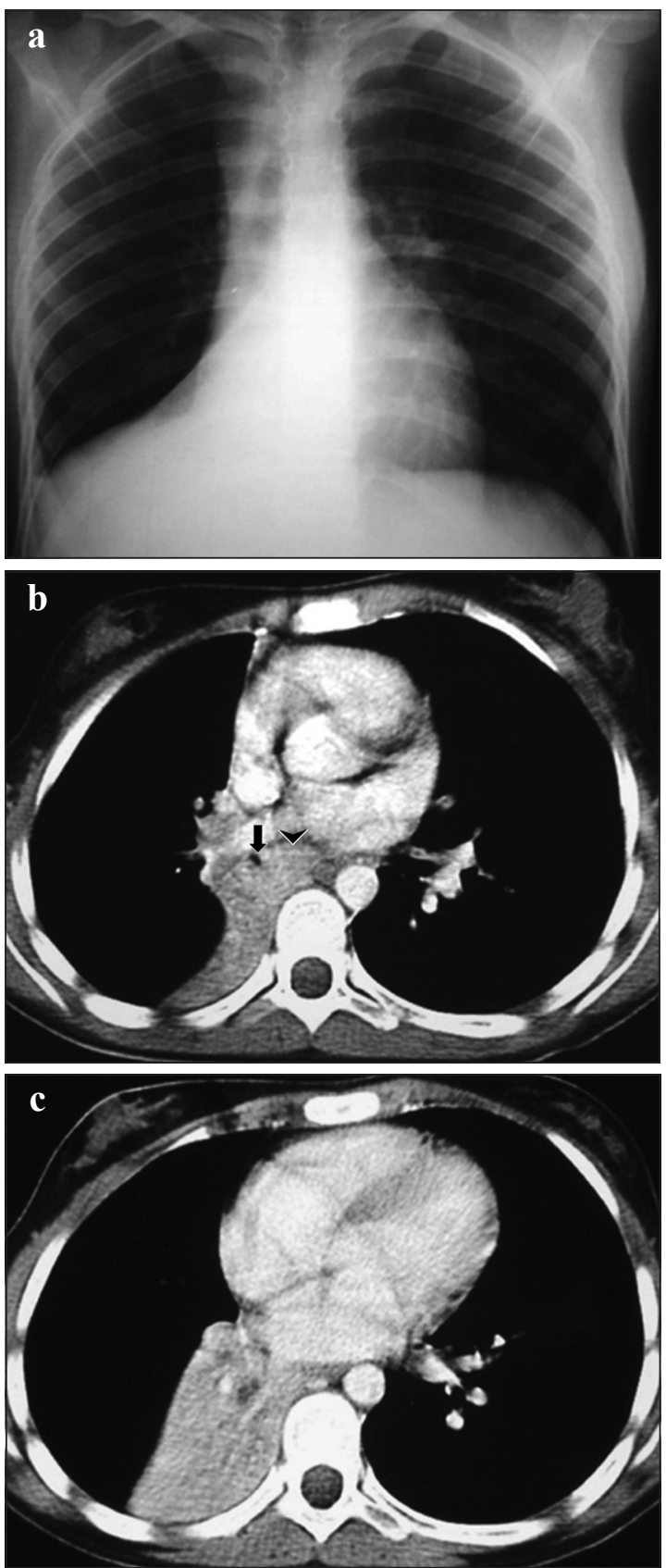

Figura 6 a-c. Tumor carcinoide bronquial: Paciente que consulta por atelectasia persistente; a) Atelectasia lóbulo inferior derecho; b) Obliteración casi total de luz bronquial (flecha), masa de difícil delimitación (punta de flecha) y componente parenquimatoso asociado a obstrucción bronquial; c) Condensación parenquimatosa sin broncograma aéreo, con realce y disminución de volumen (atelectasia). 


\section{b. Carcinoma mucoepidermoide}

El carcinoma mucoepidermoide es un raro tumor, que representa el $10 \%$ de las neoplasias pulmonares malignas en pediatría ${ }^{7}$. Se origina de las glándulas salivales menores localizadas en la submucosa respiratoria. Según sus características histológicas se dividen en tumores de grado alto, intermedio y bajo; siendo los de bajo grado los más frecuentes en niños, por lo tanto, puede haber invasión local, pero las metástasis no son frecuentes, y tienen pronóstico favorable ${ }^{21}$. Estos tumores se caracterizan por un crecimiento típicamente exofítico polipoideo, originando obstrucción bronquial, siendo esta su forma de presentación más frecuente, similar al tumor carcinoide.

En las Rx y TC de tórax se observan signos secundarios a obstrucción bronquial, como atelectasia, condensación, o atrapamiento aéreo, según el grado de obstrucción. En la lesión endobronquial se puede visualizar un marcado realce con contraste e.v., por la hipervascularidad de la lesión ${ }^{8}$. En nuestra experiencia, el único paciente con carcinoma mucoepidermoide no presentó marcado realce de la masa endobronquial luego de la administración del contraste; pero sí se advirtió un realce heterogéneo, irregular y "arracimado" del parénquima pulmonar, condicionado por la neumonía lipoidea asociada, reactiva a la obtrucción bronquial crónica (Figura 7). Adicionalmente presentó adenopatías mediastinales y paratraqueales.

\section{c. Linfoma pulmonar}

El linfoma pulmonar se asocia comúnmente a tumor mediastinal, pero como presentación pulmonar primaria aislada puede ocurrir ocasionalmente. La incidencia de linfoma pulmonar al momento del diagnóstico es de aproximadamente 5 a $10 \%$ en el linfoma Hogdkin y menos del $5 \%$ en el linfoma no Hodgkin ${ }^{22}$; incidencia que aumenta al $40 \%$ durante la evolución de la enfermedad.
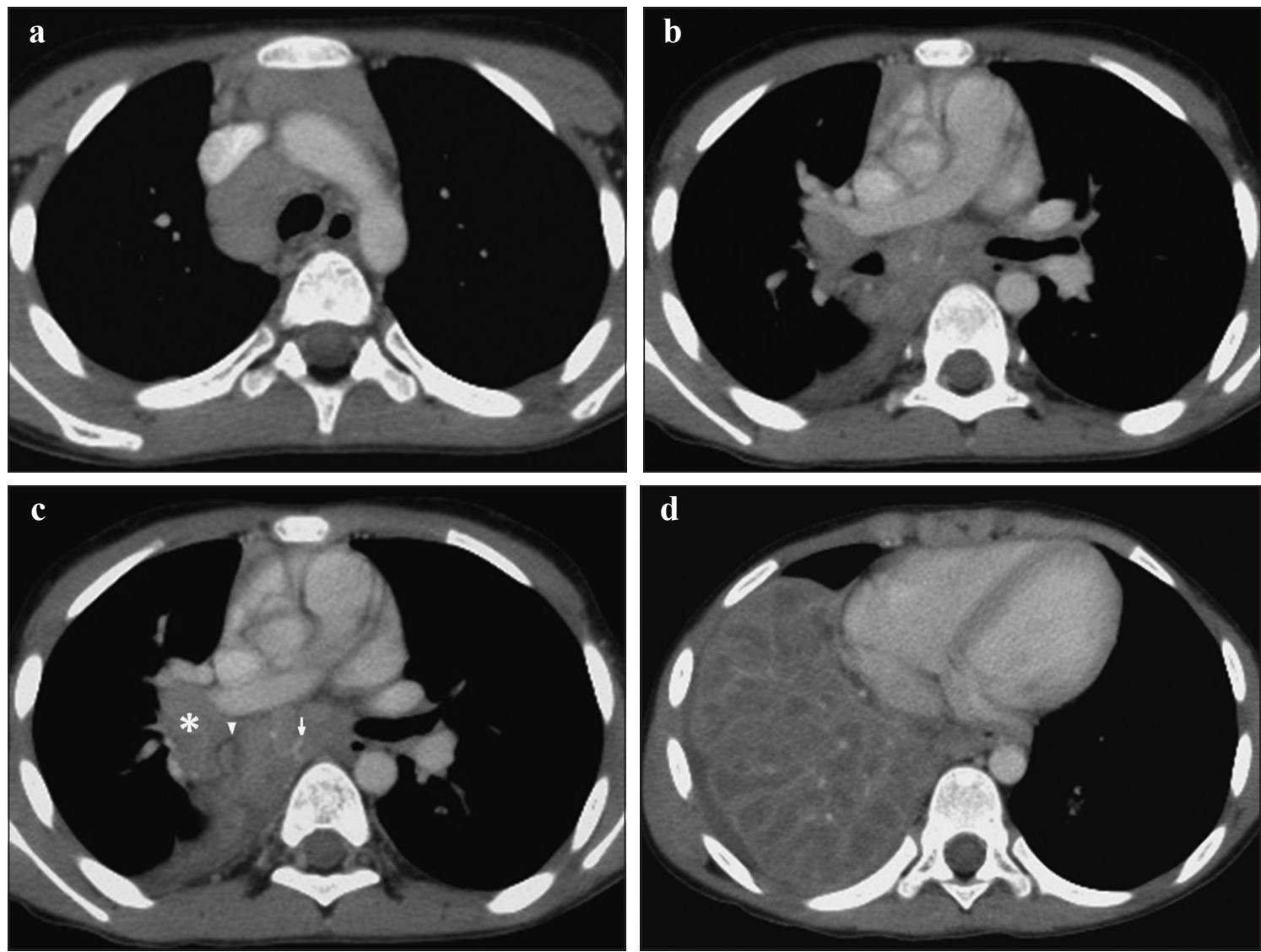

Figura 7 a-d. Carcinoma mucoepidermoide: Paciente que luego de ser tratado por neumonía, persiste con imagen radiopaca en mitad inferior de hemitórax derecho y ensanchamiento mediastinal en Rx de tórax (no mostrada); a) Adenopatía paratraqueal derecha; b) Ensanchamiento subcarinal por una masa predominantemente homogénea y adenopatía hiliar derecha; c) Ocupación total de luz bronquial derecha (punta de flecha), masa subcarinal con pequeños vasos en su interior (flecha), adenopatía hiliar (asterisco) y compromiso parenquimatoso asociado; d) Extensa afectación de lóbulo inferior derecho, donde se observa realce heterogéneo, irregular, "arracimado" del parénquima, mínimo líquido pleural. 
El hallazgo en las imágenes más frecuente es la de un nódulo pulmonar, generalmente mayor de $1 \mathrm{~cm}$ de diámetro, y menos frecuente condensación y diseminación linfangítica (Figura 8). Muy infrecuentemente se presenta como tumor endobronquial.

\section{d. Blastoma pleuropulmonar}

El blastoma pleuropulmonar (BPP) es un raro tumor pulmonar, que generalmente se observa en menores de 6 años $(90 \%)^{23}$, y representa el 8 a $15 \%$ del total de los tumores y el $72 \%$ de las neoplasias malignas pulmonares ${ }^{7}$. Es un tumor disembriogénico o disontogénico, pudiendo ser el precursor del BPP la malformación adenomatoidea quística o malformación congénita de la vía respiratoria pulmonar, es equiparable a lo que ocurre con la nefroblastomatosis y el tumor de Wilms ${ }^{15}$. Su relación con la malformación adenomatoidea quistica es controvertida, algunas hipótesis se basan en la superposición histológica entre MAQ tipo IV de la reclasificación introducida en 2002 y el blastoma pulmonar tipo I. Aunque otros autores sostienen que no existe relación entre MAQ y BPP, sino que este último se genera de novo ${ }^{24,25}$. Actualmente, se sabe que el BPP es una entidad diferente a la del blastoma pulmonar que se observa en adultos, debido a que no contiene componentes epiteliales, y está compuesto por un blastoma maligno con componentes sarcomatosos mesenquimáticos. Según la clasificación propuesta por Dehner en 1995, se dividen en tipo I, II y III según su constitución sea predominantemente quística, mixta o sólida, respectivamente; y la sobrevida a 5 años varía según el tipo, siendo de $80-85 \%$, intermedia y del 40 al $45 \%$, respectivamente ${ }^{23,24,26}$. El seguimiento debe ser muy cercano ya que puede recurrir o presentar metástasis en 30\%, en los tipos II y III, y los sitios más frecuentes son hueso y $\mathrm{SNC}^{27}$.

En el $25 \%$ de los casos existen antecedentes familiares o personales de otras neoplasias, la asociación más frecuente es con nefroma quístico, aunque también se ha reportado con meduloblastoma, rabdomiosarcoma, tumores de células embrionarias, entre otros ${ }^{7,15,23,24}$.

El BPP tipo quístico se presenta casi invariablemente en menores de 3 años de edad ${ }^{23}$, y puede ser diagnosticado prenatalmente, habitualmente en la semana 20 de gestación, con aumento progresivo de sus dimensiones hasta el momento del nacimiento; su principal diagnóstico diferencial es la MAQ, pero en esta entidad se observa un aumento progresivo de sus dimensiones en el segundo trimestre del embarazo, para luego reducir su tamaño o involucionar completamente ${ }^{26}$. Puede ser bilateral, de crecimiento sincrónico o metacrónico, se puede presentar como neumotórax espontáneo, y asociarse a enfermedad quística renal $^{28}$.

La mayoría de los blastomas pleuropulmonares se originan en topografía subpleural, generalmente en el pulmón derecho y más del $50 \%$ en los lóbulos inferiores. El aspecto tomográfico de este tumor varía acorde a la predominancia del componente quístico o sólido (Figura 9), con realce no homogéneo luego del contraste e.v., siendo profuso en el componente sólido (Figura 10); puede identificarse como una masa bien delimitada o como una lesión extensa con desplazamiento de mediastino. Cuando su tamaño es mayor de $5 \mathrm{~cm}$ al momento del diagnóstico, o se presenta con compromiso pleural o mediastinal, existe mayor posibilidad de recurrencia o metástasis, por crecimiento de elementos sarcomatosos en los subtipos II y III ${ }^{29}$.
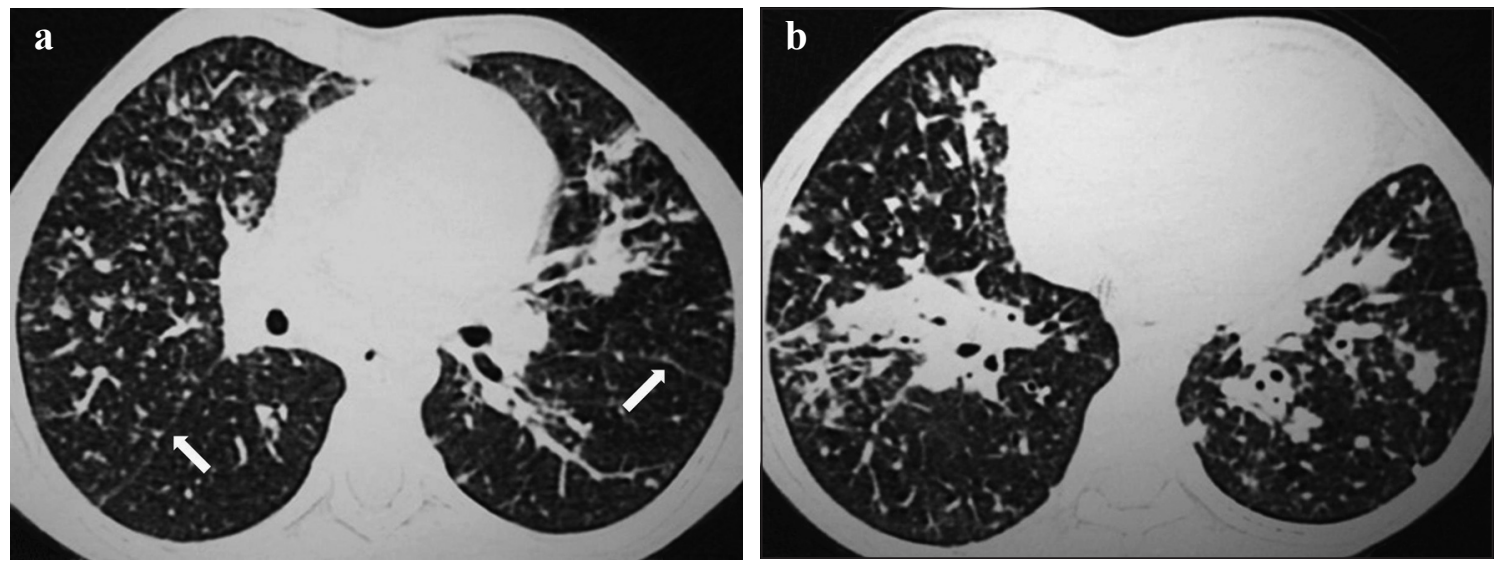

Figura 8 a,b. Linfoma. Diseminación linfangítica; a) Septos interlobulares engrosados, nódulos de distribución randomizados y tamaños variables, engrosamiento nodular de cisuras pleurales (flechas); b) Condensación, nódulos mayores $1 \mathrm{~cm}$. 


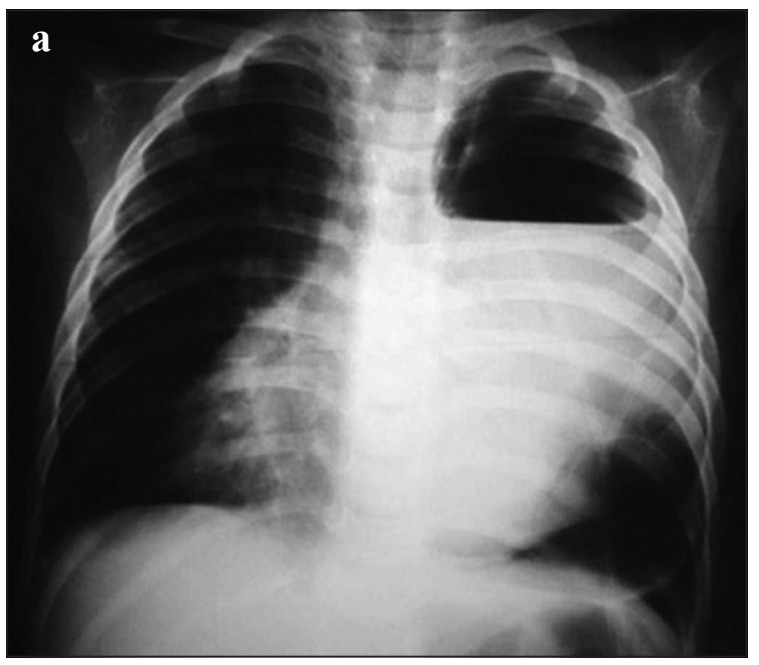

Figura 9 a-c. Blastoma pleuropulmonar quístico; a) Rx de tórax de pie: En hemitórax izquierdo se observan dos imágenes quísticas, de grandes dimensiones, la superior con nivel hidroaéreo en su interior y la inferior de bordes bien delineados; b) TC: en topografía superior de hemitórax izquierdo se observa una imagen quística con nivel hidroaéreo en su interior que condiciona desplazamiento mediastinal; c) TC: lesión quística inferior con contenido y tabique en su interior.
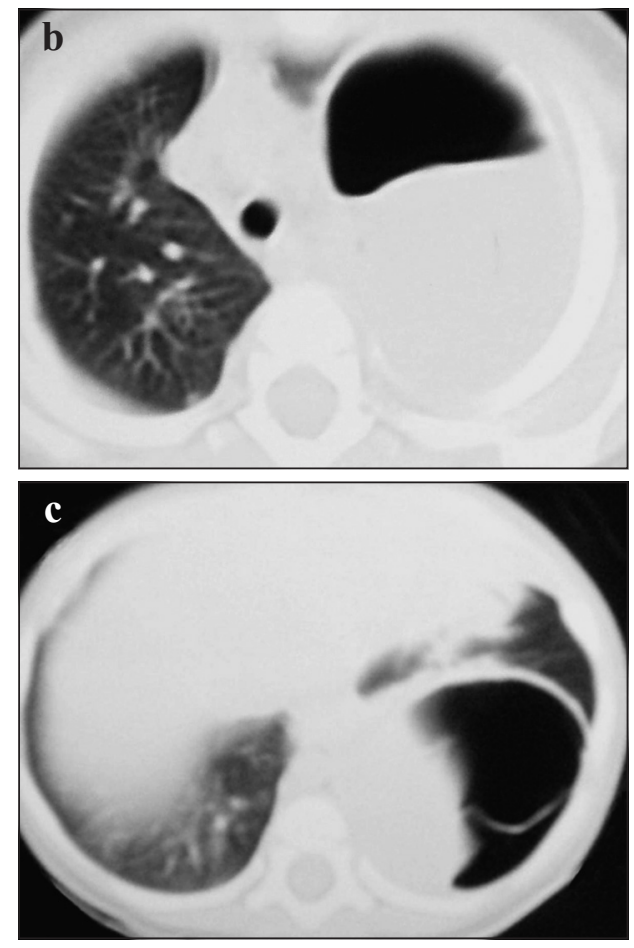
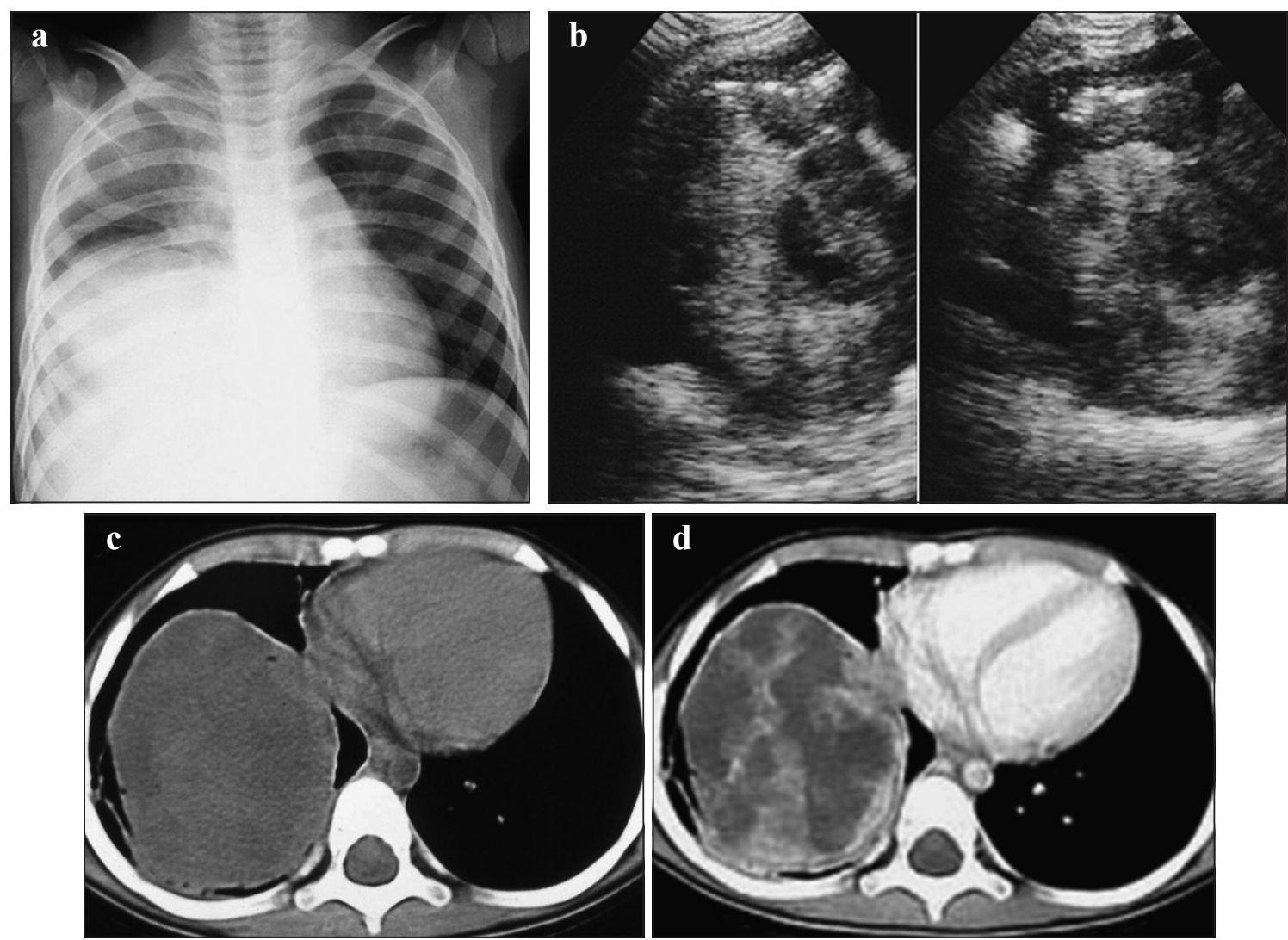

Figura 10 a-d. Blastoma pleuropulmonar sólido. a) Rx de tórax: imagen radiopaca en mitad inferior de hemitórax derecho, signo de la silueta y margen superior redondeado, mínimo despegamiento pleural superior e identificación de cisura menor; b) Ecografía: imagen redondeada heterogénea; c) TC simple: imagen redondeada, de aspecto sólido, en tórax derecho; y d) TC con contraste: realce heterogéneo y mínimo compromiso pleural asociado. 


\section{e. Metástasis pulmonares}

Las metástasis pulmonares son más frecuentes que los tumores primarios malignos, representando el $83 \%$ y $16 \%$ de los tumores pulmonares, respectivamente; según un reporte de la experiencia durante 25 años del Texas Children's Hospital'.

El parénquima pulmonar es la localización predominante de las metástasis de la mayoría de los tumores sólidos extracraneanos. El uso de la TC es rutinaria en diferentes tumores y la presencia de nódulos pulmonares cambia la estadificación inicial y el tratamiento. Al momento del diagnóstico entre 15 a 20\% de los rabdomiosarcomas, osteosarcomas y sarcomas de Ewing y un $10 \%$ de los tumores de Wilms y hepatoblastoma; presentan secundarismos pulmonares. Recientemente se ha reportado para neuroblastoma metástasis pulmonares al momento del diagnóstico en aproximadamente el 3,6\% de los $\operatorname{casos}^{30}$, a diferencia de los reportes iniciales, donde era sólo del 1\%.

En el 30 a 40\% de los niños con osteosarcoma desarrollan secundarismos pulmonares durante la evolución de su enfermedad, por lo tanto, su seguimiento debe incluir TC de rutina, al ingreso y cada 3 meses durante el tratamiento y el primer año de seguimiento post-tratamiento.

En el seguimiento de los pacientes con tumor de Wilms existen opiniones controvertidas respecto al valor pronóstico de la presencia de metástasis pulmonares en TC cuando la Rx de tórax es normal, en nuestra institución los pacientes tienen seguimiento mensual con $\mathrm{Rx}$ de tórax y trimestral con TC. Ante la presencia de un nódulo en TC debe aplicarse quimioterapia, si la lesión nodular desaparece en los próximos controles sería porque la lesión era una atelectasia, proceso infeccioso, un artefacto o porque la mestástasis realmente respondió a la quimioterapia.

La presencia de múltiples nódulos pulmonares en niños con un tumor sólido maligno conocido, en especial cuando alguna de ellas es mayor de 1 $\mathrm{cm}$ de diámetro, son invariablemente indicativos de metástasis (Figura 11). En las regiones endémicas, hay que tener en cuenta que infecciones como tuberculosis o histoplasmosis pueden presentarse como múltiples imágenes nodulares (Figura 12). Otros diagnósticos diferenciales de múltiples nódulos son embolias sépticas, varicela previa con compromiso pulmonar (granulomas clacificados), granulomatosis de Wegener, papilomatosis laríngea, e infecciones oportunistas en pacientes inmunodeficientes.

Los problemas diagnósticos se originan ante la presencia de imágenes nodulares únicas o muy pequeñas (escasos milímetros); en estos casos las reconstrucciones multiplanares que se puede realizar luego de obtener imágenes con MDCT, permiten mejorar la sensibilidad del método, incluso la realización de reconstrucciones MIP (imágenes de máxima intensidad de proyección) son de gran utilidad (Figura 13), ya que permite diferenciar los pequeños nódulos de pequeñas estructuras vasculares que se representan como estructuras tubulares o arborizadas, también resulta útil el
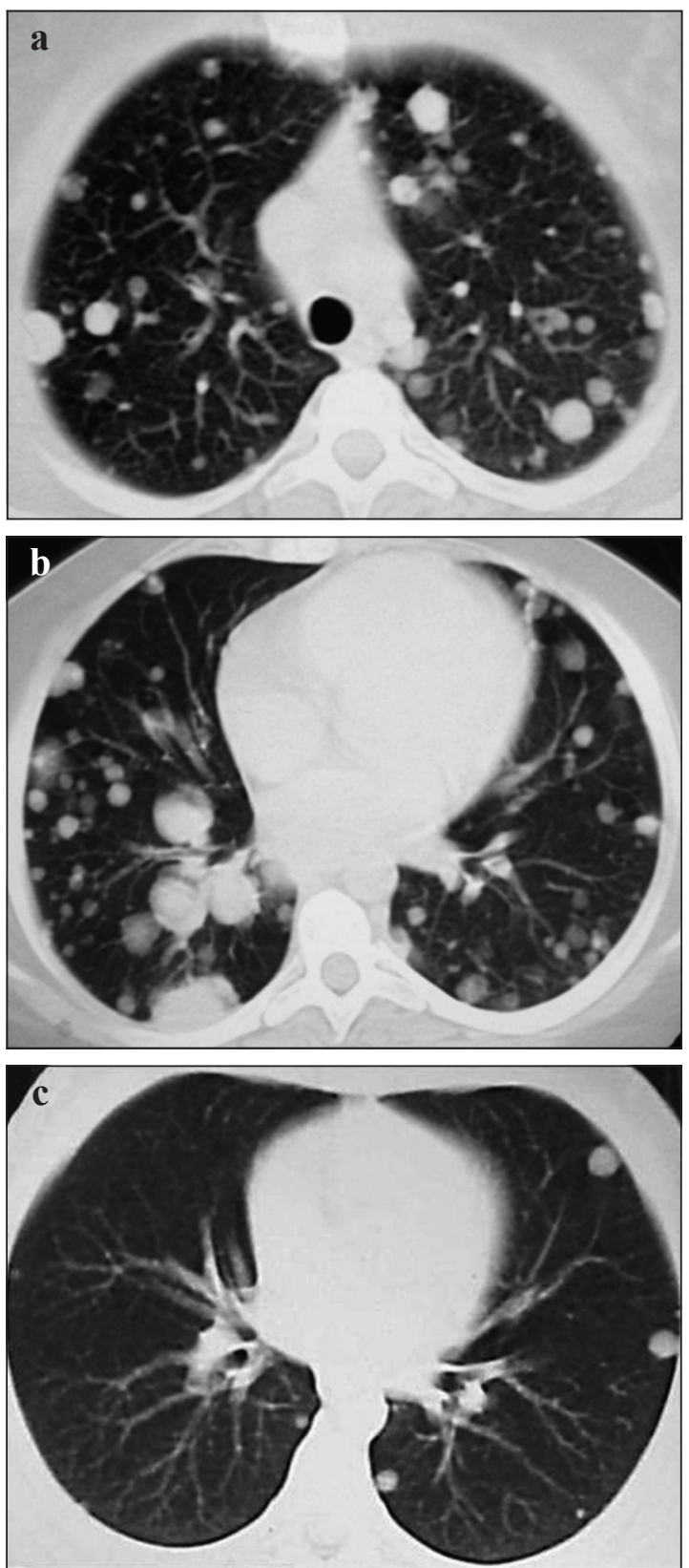

Figura 11 a-c. Metástasis pulmonares. Sarcoma alveolar (a, b), múltiples nódulos pulmonares, de tamaños variables y márgenes bien definidos, conformando aspecto en suelta de globos. Tumor de Wilms (c), nódulos subpleurales. 


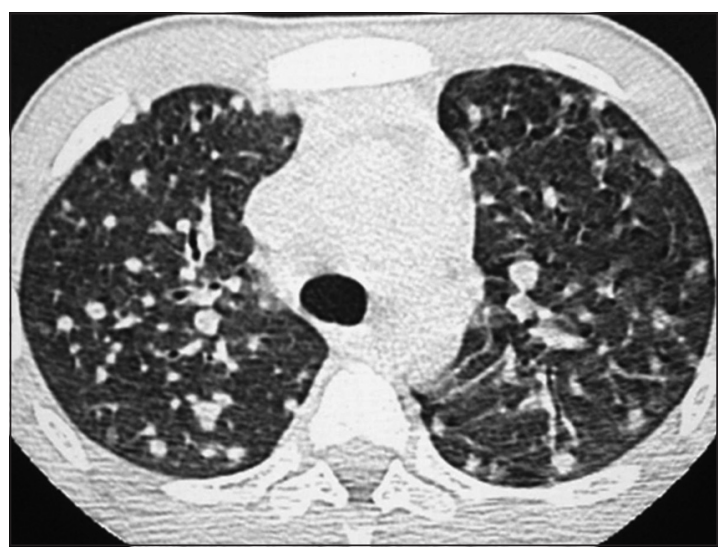

Figura 12. Histoplasmosis en paciente inmunodeficiente (SIDA enfermedad). TC con múltiples imágenes nodulares, distribución randomizada.

análisis de las lesiones dudosas en imágenes contiguas; otro método que podría colaborar en discernir el origen de las imágenes es cambiar de decúbito al paciente al momento de adquirir las imágenes, ya que los tractos vasculares modifican su morfología y las imágenes metastásicas mantienen sus características. Si a pesar de todo, la pequeña imagen nodular continúa siendo un problema o dilema diagnóstico, se recomienda realizar un control en 6 a 8 semanas, para evaluar su persistencia y cambios en sus características.

Han sido muchas las publicaciones y los esfuerzos realizados por diferentes grupos de trabajo para tratar de aportar información concluyente que permita diferenciar las características tomográficas de los nódulos benignos y malignos en pacientes pediátricos con tumores malignos sólidos en seguimiento. En los pacientes adultos, la presencia de una imagen nodular mayor de $5 \mathrm{~mm}$, el realce de la imagen luego de la administración de contraste ev, y los márgenes irregulares o espiculados son altamente sugestivos de malignidad. En los niños las metástasis generalmente son múltiples, de localización subpleural, predominantemente basales, redondeadas y bien circunscriptas. Mc Carville y colaboradores demostraron que pueden coexistir las imágenes nodulares benignas y malignas en un mismo paciente, y que los mayores predictores de malignidad entre los hallazgos tomográficos es la aparición de nuevos nódulos en controles progresivos y los márgenes bien circunscriptos a diferencia de adultos; otro factor predictivo es la bilateralidad de las lesiones ${ }^{31}$. En una publicación de 2010, Torres Silva-Amaral y cols., hallaron que los nódulos menores de $5 \mathrm{~mm}$ tienen mayor probabilidad de ser benignos, y a pesar de demos-

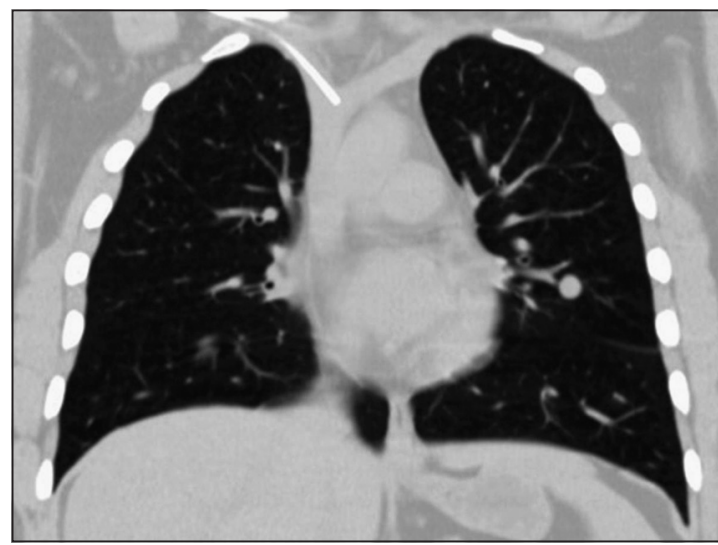

Figura 13. Metástasis pulmonar, reconstrucción multiplanar TC que muestra la relación de los nódulos con la vasculatura.

trar que esta relación 9/1, no tuvo correlación estadísticamente significativa; concluyendo que los nódulos pulmonares en niños con tumores malignos muestran patrones tomográficos variables; y que ninguna de las variables analizadas (tamaño, localización, número de lesiones, márgenes, etc) permiten diferenciar de modo confiable entre benignidad y malignidad ${ }^{32}$.

También se ha publicado la experiencia inicial en la aplicación del sistema de detección computada de nódulos pulmonares en niños ${ }^{33}$, si bien no se utilizó para hacer diagnóstico diferencial entre benignidad y malignidad, se intentó demostrar su valor para el diagnóstico de los nódulos en comparación con el diagnóstico realizado por cuatro radiólogos experimentados, siendo la conclusión de esta publicación que el sistema automatizado de detección de nódulos es útil como segundo lector en nódulos mayores de $4 \mathrm{~mm}$, pero considerablemente menos sensible para nódulos de menor tamaño.

En los casos que los nódulos pulmonares no corresponden a metástasis, sino a lesiones benignas observables en un tercio de los pacientes, las histologías más frecuentemente encontradas son ganglios linfáticos intrapulmonares, cicatrices, secundarias a reacción medicamentosa, vasculitis, tumor miofibroblástico inflamatorio; y ocasionalmente un segundo tumor ${ }^{15,34}$.

Las metástasis generalmente son de aspecto sólido, pero algunos tumores pueden presentar metástasis excavadas, como el sarcoma, linfoma de Hodgkin y ocasionalmente el tumor de Wilms. Las metástasis de osteosarcoma pueden calcificarse, comprometer pleura, adenopatías mediastinales e incluso pericardio y corazón (Figura 14). 

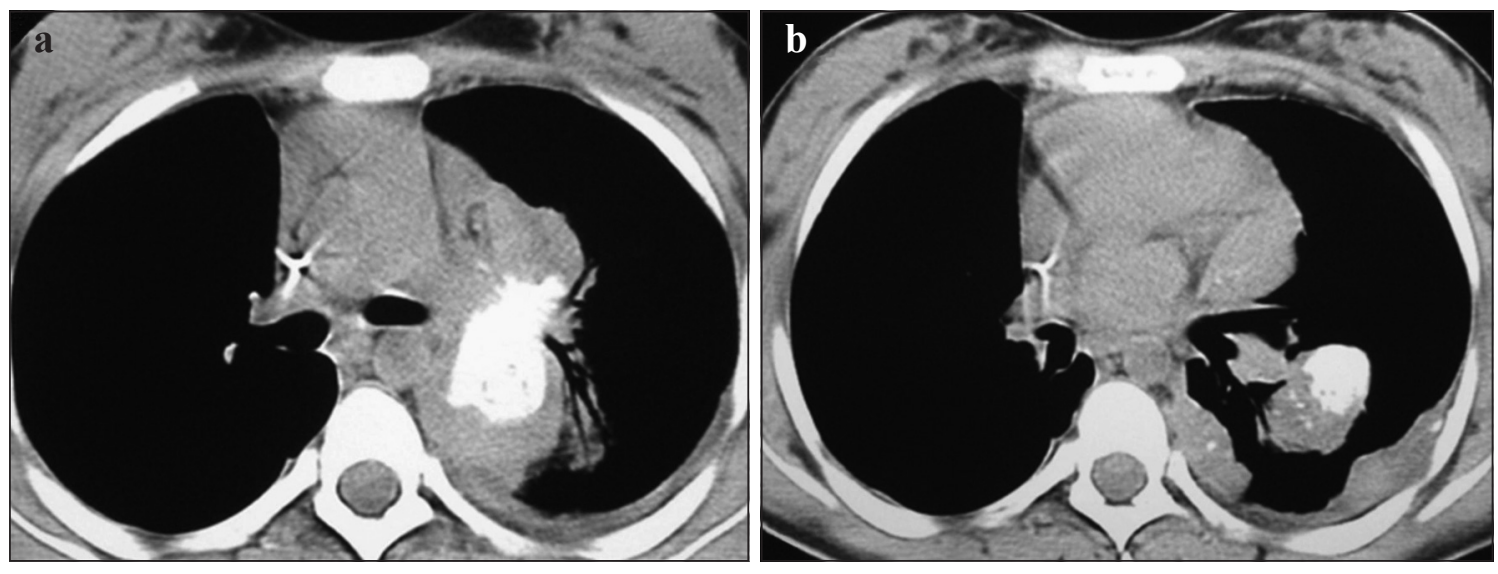

Figura 14 a, b. Metástasis de osteosarcoma. a) Gran masa yutamediastinal e hiliar izquierda con calcificaciones densas y extensas en su interior, mínimo líquido pleural asociado; y b) masa pulmonar izquierda, mayor de $2 \mathrm{~cm}$ de diámetro, con calcificaciones; engrosamiento nodular de la pleura con calcificaciones puntiformes.

\section{Conclusiones}

Los tumores pulmonares en pediatría son infrecuentes. El espectro de los tumores benignos es muy amplio, los tumores broncopulmonares primarios malignos son muy poco frecuentes a diferencia de las metástasis pulmonares, las cuales representan la mayoría de los tumores malignos en los niños. El diagnóstico de las neoplasias primarias pulmonares frecuentemente es tardío, por su baja incidencia y la falta de sospecha clínica o por su presentación atípica. Los hallazgos radiológicos y tomográficos de los tumores pulmonares no son específicos en la mayoría de los casos, constituyendo habitualmente un gran desafío diagnóstico.

\section{Bibliografía}

1.- SLOVIS T L. The ALARA (as low as reasonably achievable) concept in pediatric CT: intelligent dose reduction. Multidisciplinary conference organized by the Society for Pediatric Radiology, August 18-19, 2001. Pediatr Radiol 2002; 32: 217-313.

2.- NEWMAN B. Thoracic neoplasm in children. Radiol Clin N Am 2011; 49: 633-64.

3.- GUINEE D G Jr. Update on Nonneoplastic Pulmonary Lymphoproliferative Disorders and Related Entities. Arch Pathol Lab Med 2010; 134:691-701.

4.- ZEN Y, KITAGAWA S, MINATO H, KURUMAYA H, KATAYANAGI K, MASUDA S, et al. IgG4-positive plasma cells in inflammatory pseudotumor (plasma cell granuloma) of the lung. Hum Pathol 2005; 36: 710-7.

5.- MERGAN F, JAUBERT F, SAUVAT F, HARTMANN O, LORTAT-JACOB S, RÉVILLON Y, et al. Inflamatory myofibroblastic tumor in children: clinical review with anaplastic lymphoma kinase, Epstein-Barr virus and human herpes virus 8 detection analysis. J Pediatr Surg 2005; 40: 1581-6.

6.- SNYDER C S, DELL'AQUILA M, HAGHIGHI P, BAERGEN R N, SUH Y K, YI E S. Clonal changes in inflammatory pseudotumor of the lung: a case report. Cancer 1995; 76: 1545-9.

7.- DISHOP M, KURUVILLA S. Primary and Metastatic Lung Tumors in the Pediatric Population. A Review and 25-Year Experience at a Large Children's Hospital. Arch Pathol Lab Med 2008; 132: 1079-103.

8.- MC HUGH K. Chest Tumours Other than Lymphoma. In: J. Lucaya, J. L. Strife, eds. Pediatric Chest Imaging. Chest Imaging in Infants and Children, 2nd Revised Edition. Springer-Verlag Berlin Heidelberg 2008, Capítulo 12; p 263- 87.

9.- JANIK J S, JANIK J P, LOVELL M A, HENDRICKSON R J, BENSARD D D, GREFFE B S. Recurrent inflammatory pseudotumors in children. J Pediatr Surg 2003; 38: 1491-5.

10.- KRADIN R L, MARK E J. Benign lymphoid disorders of the lung, with a theory regarding their development. Hum Pathol 1983; 14: 857-67.

11.- SONG M K, SEOL Y M, PARK Y E, KIM Y S, LEE M $\mathrm{K}$, LEE C H, et al. Pulmonary nodular lymphoid hyperplasia associated with Sjo" gren's syndrome. Korean J Intern Med 2007; 22: 192-6.

12.- KAJIWARA S, SAKAI S, SOEDA H, TAKAHASHI N, OKAFUJI T, YOSHIMITSU K, et al. Multifocal nodular lymphoid hyperplasia of the lung. J Thorac Imaging 2005; 20: 239-41.

13.- ABBONDANZO S L, RUSH W, BIJWAARD K E, KOSS M N. Nodular lymphoid hyperplasia of the lung: a clinicopathologic study of 14 cases. Am J Surg Pathol 2000; 24: 587-97.

14.- BÉGUERET H, VERGIER B, PARRENS M, LEHOURS P, LAURENT F, VERNEJOUX J M, et al. Primary lung small B-cell lymphoma versus lymphoid 
hyperplasia: evaluation of diagnostic criteria in $26 \mathrm{ca}-$ ses. Am J Surg Pathol 2002; 26: 76-81.

15.- NEWMAN B, EFFMANN E L. Lung masses. In: Slovis T, editor. Caffey's pediatric diagnostic imaging, vol. 1 . 11th edition. Philadelphia: Mosby Elsevier; 2008. p. 1294-323.

16.- HANCOCK B J, DI LORENZO M, YOUSSEF S, YAZBECK S, MARCOTTE J E, COLLIN P P. Childhood primary pulmonary neoplasms. J Pediatr Surg 1993; 28: 1133-6.

17.- MCCAHON E. Lung tumours in children. Paediatr Respir Rev. 2006; 7: 191-6.

18.- CHONG S, LEE K S, CHUNG M J, HAN J, KWON O J, KIM T S. Neuroendocrine tumors of the lung: clinical, pathologic, and imaging findings. RadioGraphics 2006; 26: 41-57.

19.- WANG L T, WILKINS E W Jr, BODE H H. Bronchial carcinoid tumors in pediatric patients. Chest 1993; 103: 1426-8.

20.- LACK E E, HARRIS G B C, ERAKLIS A J, VAWTER G F. Primary bronchial tumors in childhood: a clinicopathologic study of six cases. Cancer 1983; 51: 492-7.

21.- WELSH J H, MAXSON T, JAKSIC T, SHAHAB I, HICKS J. Tracheobronchial mucoepidermoid carcinoma in childhood and adolescence: case report and review of the literature. Int J Pediatr Otorhinolaryngol 1998; 45: 265-73.

22.- LEONE G, CASTELLANA M, RABITTI C, SICA S, DE GREGORIO F, FALAPPA P. Escavative pulmonary Hodgkin's lymphoma: diagnosis by cutting needle biopsy. Eur J Haematol 1990; 44: 139-41.

23.- PRIEST J R, WATTERSON J, STRONG L, HUFF V, WOODS W G, BYRD R L, et al. Pleuropulmonary blastoma: a marker for familial disease. J Pediatr 1996; 128: 220-4.

24.- HILL D A, JARZEMBOWSKI J A, PRIEST J R, WILLIAMS G, SCHOETTLER P, DEHNER L P. Type I pleuropulmonary blastoma: pathology and biology study of 51 cases from the international pleuropulmonary blastoma registry. Am J Surg Pathol 2008; 32: 282-95.

25.- DEHNER L P. Beware of "degenerating" congenital pulmonary cysts. Pediatr Surg Int 2005; 21: 123-4.

26.- MINIATI D N, CHINTAGUMPALA M, LANGSTON C, DISHOP M K, OLUTOYE O O, NUCHTERN J G, et al. Prenatal presentation and outcome of children with pleuropulmonary blastoma. J Pediatr Surg 2006; 41: 6671.

27.- PRIEST J R, MCDERMOTT M B, BHATIA S, WATTERSON J, MANIVEL J C, DEHNER L P. Pleuropulmonary blastoma: a clinicopathologic study of 50 cases. Cancer 1997; 80: 147-61.

28.- PRIEST J R, WILLIAMS G M, HILL D A, DEHNER L P, JAFFÉ A. Pulmonary Cysts in Early Childhood and the Risk of Malignancy. Pediatric Pulmonology 2009; 44: $14-30$

29.- PRIEST J R, HILL D A, WILLIAMS G M, MOERTEL C L, MESSINGER Y, FINKELSTEIN M J, et al. Type I Pleuropulmonary blastoma: a report from the International Pleuropulmonary Blastoma Registry. J Clin Oncol 2006; 24: 4492-8.

30.- DUBOIS S G, LONDON W B, ZHANG Y, MATTHAY K K, MONCLAIR T, AMBROS P F, et al. Lung Metastases in Neuroblastoma at Initial Diagnosis: A Report from the International Neuroblastoma Risk Group (INRG) Project. Pediatr Blood Cancer 2008; 51: 589-92.

31.- MCCARVILLE M B, LEDERMAN H M, SANTANA V M, DAW N C, SHOCHAT S J, LI C S, et al. Distinguishing benign from malignant pulmonary nodules with helical chest $\mathrm{CT}$ in children with malignant solid tumors. Radiology 2006; 239: 514-20.

32.- SILVA C T, AMARAL J G, MOINEDDIN R, DODA W, BABYN P S. CT Characteristics of Lung Nodules Present at Diagnosis of Extrapulmonary Malignancy in Children. AJR 2010; 194: 772-8.

33.- HELM E J, SILVA C T, ROBERTS H C, MANSON D, SEED M T, AMARAL J G, et al. Computer-aided detection for the identification of pulmonary nodules in pediatric oncology patients: initial experience. Pediatr Radiol 2009; 39: 685-93.

34.- EGGLI K D, NEWMAN B. Nodules, masses, and pseudomasses in the pediatric lung. Radiol Clin North Am 1993; 31: 651-66.

Correspondencia a:

Dra. María Elena Ucar G.

Servicio de Radiología y Diagnóstico por Imágenes,

Hospital de Niños Sor María Ludovica.

La Plata. Argentina.

E-mail: pepaucar@hotmail.com 